\title{
A values-based perspective on good practice in compulsion
}

\author{
Invited Commentary on ... Detained - What's my Choice? Part $1^{\dagger}$ \\ K. W. M. Fulford \& Malcolm King
}

Abstract We outline how the values-based approach adopted in training materials supporting the Mental Health Act 2007 for England and Wales will complement recovery-based practice in compulsory psychiatric detention.

Roberts et al's (2008, this issue) article is timely in facing up to the issues surrounding compulsion as requiring, no less than other aspects of mental health, a positive approach to good practice.

Many regard compulsion as a failure of good practice. Roberts et al make clear that this is not necessarily the case. By its nature, compulsion is more prone to misuse than most other interventions. Hence the need for safeguards. Safeguards in themselves, however, will not ensure good practice. What is needed, in addition, is the positive approach to recovery and the development of the skills of selfmanagement for which the article so clearly argues. The training materials to support implementation of the new Mental Health Act 2007 for England and Wales are being developed in a strongly values-based context that directly complements that approach (see http:/ / mhact.csip.org.uk).

Values-based practice is a skills-based approach to working with complex and conflicting values in health and social care (Fulford, 1989; Woodbridge \& Fulford, 2004). The approach is relevant to compulsion essentially because compulsion involves a direct conflict of values between the person concerned and everyone else.

The training materials for the Mental Health Act 2007 are being set directly within a values-based approach in two ways. First, these materials, instead

${ }^{+}$To be read in conjunction with pp. 172-180, 181-182 and 184-186, this issue. of being produced 'top-down' from the changes in the law, build on a series of case studies that are being produced by people with direct personal experience of key areas of particular difficulty in compulsion (Dora Jonathan, a lawyer from the Black and minority ethnic community with extensive experience of work on mental health tribunals, and Sarah Dewey, a service user researcher with personal experience of compulsion). This 'bottom-up' approach aims to build into the training materials the values and experiences of those directly concerned, as the starting point for a values-based approach to good practice in compulsion.

Second, the training materials focus particularly on the Guiding Principles that will be given in the Code of Practice (publication expected in April 2008). These are central to a values-based approach because they provide a framework of values for balanced decision-making. Thus, the law tells us 'what to do'; the Code of Practice tells us 'how to do it'; and the Guiding Principles, set within a values-based approach, guide us in applying the law and Code of Practice in the particular circumstances of each individual case.

Corresponding with their importance for good practice in compulsion, the Guiding Principles have a considerably enhanced status in the Mental Health Act 2007: thus, the areas that the Guiding Principles must cover (hence the values that they must embody) are given statutory force by a statement of principles in the Act; and the Guiding Principles themselves, in addition to being set out

K. W. M. Fulford is Professor of Philosophy and Mental Health at the University of Warwick (Room A-133, Medical School, University of Warwick, Coventry CV4 7AL, UK. Email: k.w.m.fulford@warwick.ac.uk), Honorary Consultant Psychiatrist and Fellow of St Cross College at the University of Oxford, Co-Director of the Institute for Philosophy, Diversity and Mental Health at the University of Central Lancashire's Centre for Ethnicity and Health, and Special Adviser for Values-Based Practice at the Department of Health, London. Malcolm King, of the Care Services Improvement Partnership, is National Training Lead on the Mental Health Act 2007 Implementation Team, and National Training Lead on Values-Based Practice with the Focused Implementation Site Programme for Delivering Race Equality in Mental Health Care. 
in full in Chapter 1 of the Code of Practice, will be referred to throughout the Code. We believe that this enhanced status, together with the embedding of the training materials in a strongly values-based approach, provides an opportunity to move mental health practice in compulsion firmly towards the recovery-based approach advocated by Roberts and his co-authors.

\section{Declaration of interest}

K.W.M.F and M.K. are both involved in developing the training materials to support the Mental Health
Act 2007, M.K. as National Training Lead on the Implementation of the Care Services Improvement Partnership, and K.W.M.F as Special Adviser for Values-Based Practice at the Department of Health.

\section{References}

Fulford, K. W. M. (1989) Moral Theory and Medical Practice. Cambridge University Press.

Roberts, G., Dorkins, E., Wooldridge, J. \& Hewis, E. (2008) Detained - what's my choice? Part 1: Discussion. Advances in Psychiatric Treatment, 12, 172-180.

Woodbridge, K. \& Fulford, K. W. M. (2004) Whose Values? A Workbook for Values-Based Practice in Mental Health Care. Sainsbury Centre for Mental Health.

\title{
Detained - what's my choice? Part 2: Conclusions and recommendations ${ }^{\dagger}$
}

\author{
Eluned Dorkins, Glenn Roberts, James Wooldridge \\ \& Elaine Hewis
}

\begin{abstract}
We have developed this succession of articles as a series of iterative steps, each seeking to uphold the recovery values of co-working and collaboration, looking for agreement and commonality but valuing equally diverse viewpoints and difference. Our conclusion is that this is the beginning of a creative dialogue on choice as a route to recovery for people who are psychiatrically detained. We commend our method of engaging with the inevitable tensions and dilemmas by: clarifying the story behind difficult interactions, identifying the relevant guiding principles and jointly working to explore from different viewpoints what can be done to promote recovery.
\end{abstract}

There can sometimes seem to be unbridgeable chasms of perspective between professionals and detained patients. Our aim was to examine some of these differences and talk together about how best to work in service of the common aim of recovery.

${ }^{+}$To be read in conjunction with pp. 172-180, 181-182 and $183-184$, this issue.
We are grateful to our commentators for putting our observations and viewpoints (Roberts et al, 2008, this issue) in a broader context. Fulford \& King (2008, this issue) offer an intriguing glimpse into future guidance on working with people subject to compulsory treatment. They illustrate a close parallel to our own method of working to clarify guiding principles through which values can be applied to specific situations.

Eluned Dorkins is a consultant forensic psychiatrist at Langdon Hospital, Dawlish, Devon. Glenn Roberts is a consultant in rehabilitation and recovery in Devon (Wonford House Hospital, Dryden Road, Exeter EX2 5AF, UK. Email: glennroberts@doctors.org.uk). James Wooldridge is a service avoider, freelance trainer/consultant/speaker and regional coordinator for the Open Up project. Elaine Hewis is a survivor and carer, consultant trainer and lecturer in mental health issues. 